\title{
ANTONIO GRAMSCI E ALTERIDADE: A RELAÇÃO DIRIGENTE/DIRIGIDO
}

Claudio Reis ${ }^{1}$

RESUMO: A relação entre dirigente/dirigido é para o pensador e militante italiano Antonio Gramsci uma questão fundamental da ciência política e das ciências sociais em geral. A sua preocupação com tal problema pode ser percebida tanto nos seus trabalhos pré-carcerários quanto nos Quaderni. No presente artigo, essa relação terá como mediação central o tema da alteridade, entendida como uma perspectiva cultural e política progressista.

Palavras-chave: Antonio Gramsci. Alteridade. Relação Dirigente/Dirigido.

\section{ANTONIO GRAMSCI AND ALTERITY: THE RELATION BETWEEN THE RULER AND THE RULED}

ABSTRACT: For the thinker and militant Antonio Gramsci the relation between the ruler and the ruled is a fundamental issue in political science and in social science as a whole. His concern about this problem can be found in the work done before he was jailed and in the Quaderni. In the current article, this relation will be analysed in terms of alterity, which can be undestood in a progressist cultural and political perspective.

Keywords: Antonio Gramsci. Alterity. Relation between the ruler and the ruled.

\section{ANTONIO GRAMSCI Y ALTERIDAD: LA RELACIÓN DIRIGENTE / DIRIGIDO}

RESUMEN: La relación entre dirigente / dirigido es para el pensador y militante italiano Antonio Gramsci una cuestión fundamental de la ciencia política y de las ciencias sociales en general. Su preocupación por este problema puede ser percibida tanto en sus trabajos precarcelarios como en los Quaderni. En el presente artículo, esa relación tendrá como

\footnotetext{
${ }^{1}$ Doutor em Ciências Sociais pela Unicamp, Professor de Teoria Política da FCH/UFGD. Membro do Conselho Nacional da International Gramsci Society - Brasil (Biênio 2017-2019). Endereço eletrônico: claudio.reiss@yahoo.com.br.
} 
mediación central el tema de la alteridad, entendida como una perspectiva cultural y política progresista.

Palavras Clave: Antonio Gramsci. Alteridad. Relación Dirigente / Dirigido.

\section{Introdução}

A discussão a ser desenvolvida no presente trabalho não tem como pretensão finalizar a sua problemática, mas sim dar mais um passo na direção do entendimento sobre a possível relação entre o posicionamento político-cultural de Antonio Gramsci e a dimensão da alteridade.

Inicialmente é interessante notar como o autor sardo/italiano se manteve distante da ciência social da época, de cunho positivista. Esse posicionamento o fez se distanciar de leituras esquemáticas e hierárquicas quanto aos grupos e as classes sociais subalternos. Nos Quaderni del Carcere, o autor situa Cesare Lombroso, considerado um importante antropólogo criminal da época, no seguinte quadro intelectual italiano:

\footnotetext{
Ademais também este fenômeno tem uma origem histórica e não é de modo algum uma qualidade fatal do homem italiano: o materialismo histórico de Graziadei se assemelha ao de Ferri, de Niceforo, de Lombroso, de Sergi, e se sabe que função histórica teve essa concepção biológica da "barbárie" atribuída aos sulistas (aliás, aos sujos) na política da classe dirigente italiana (GRAMSCI, 2001, V.2, p. 879).
}

Portanto, no interior da luta política dos comunistas, em sua busca pela hegemonia da classe operária e dos grupos subalternos da Itália, a desconstrução do pensamento antropológico, de cunho biologista, era fundamental. As consequências de tal ideologia sobre os trabalhadores do Norte italiano, teve um importante impacto para o enfraquecimento da unidade operário-camponesa naquele território. Certamente, esse aspecto fez o autor se distanciar daquilo que era considerado como pensamento antropológico. Todavia, mesmo tendo uma postura como essa, Gramsci não desconsiderou a importância de dimensões como a cultural, por exemplo. Além disso, trouxe contribuições para se pensar uma forma de alteridade, tendo em vista a luta político-ideológica dos comunistas.

De qualquer forma, essa relação entre a teoria social gramsciana e a antropologia não se apresenta de maneira "clássica", isto é, não parece ser tarefa central de Gramsci desenvolver um pensamento antropológico, pelo menos do modo como essa ciência social se elabora. O autor não busca, por exemplo, pesquisar sociedades tradicionais localizadas fora do Ocidente. Nem mesmo sinaliza a intenção de desenvolver um método científico específico a ser praticado num determinado "trabalho de campo". Isso ocorre pelo fato de Gramsci não ser um 
antropólogo stricto sensu, ou seja, como um representante próprio da antropologia. O mesmo ocorre em relação às outras áreas das ciências humanas. Gramsci, na verdade, pensa a realidade social em sua totalidade e busca criar um pensamento a-disciplinar. Como afirma Renato Ortiz:

\footnotetext{
"Seria Gramsci um sociólogo?", "Um cientista político?", penso que esse tipo de questão leva a formular um conjunto de falsos problemas, pois, como marxista e militante, suas preocupações transbordavam as fronteiras disciplinares e tinham como referência direta o campo da prática política (ORTIZ, 2006, p. 95).
}

Desse modo, o fato dele não se enquadrar especificamente como um antropólogo, não significa dizer que em suas ideias não existam certos princípios antropológicos.

Antonio Gramsci é um marxista, dos mais fecundos no interior dessa tradição de pensamento e que pode ser um elo importante entre o próprio marxismo e a antropologia, tanto no sentido do primeiro contribuir à segunda, quanto o inverso.

\title{
2 A Antropologia e o tema da alteridade
}

Aqui não será feita uma abordagem minuciosa e profunda acerca da relação entre antropologia e alteridade, mas apenas alguns apontamentos gerais. Isso para contextualizar minimamente as contribuições gramscianas sobre o tema.

De maneira geral, pode-se dizer que um dos recortes analíticos prioritários da antropologia sobre a realidade, corresponda ao tema da alteridade. Desde o seu surgimento, essa área das ciências humanas tem privilegiado a análise sobre a relação que se tem, ou se deveria ter, um determinado sujeito/grupo/sociedade em relação ao outro.

\begin{abstract}
As sociedades estudadas pelos primeiros antropólogos são sociedades longínquas às quais são atribuídas as seguintes características: sociedades de dimensões restritas; que tiveram poucos contatos com os grupos vizinhos; cuja tecnologia é pouco desenvolvida em relação à nossa; e nas quais há uma menor especialização das atividades e funções sociais. São também qualificadas de "simples"; em consequência, elas irão permitir a compreensão, como uma situação de laboratório, da organização "complexa" de nossas próprias sociedades (LAPLANTINE, 2003, p.14$15)$.
\end{abstract}

Portanto, em seu início, a antropologia definiu o seu objeto específico de análise as populações externas ao mundo Ocidental - entenda-se França, Inglaterra e Estados Unidos. A sua delimitação de área surgiu historicamente, no mesmo contexto de parte significativa das ciências sociais modernas. Apenas no século XVIII

é que começa a se constituir um saber científico (ou pretensamente científico) que toma o homem como objeto de conhecimento, e não mais a natureza; apenas nessa época é que o espírito científico pensa, pela primeira vez, em aplicar ao próprio 
homem os métodos até antão utilizados na área física ou da biologia (LAPLANTINE, 2003, p.13).

Todavia é a partir da segunda metade do século XIX que a antropologia "se atribui objetos empíricos autônomos: as sociedades então ditas 'primitivas', ou seja, exteriores às áreas das civilizações europeias ou norte-americanas" (LAPLANTINE, 2003, p.14). Neste momento, como se vê, a antropologia se fazia com um olhar de superioridade do "civilizado" sobre o “primitivo". Expressava, num certo sentido, a relação dos impérios sobre as colônias:

os museus, assim, surgem abrindo uma área para os troféus que o Imperium, em virtude de sua superioridade, um dia resolveu reunir. E o colecionador do museu, como administrador colonial e o nosso antropólogo vitoriano, sendo sua tarefa a de obter exemplares típicos das etapas pelas quais tem caminhado a humanidade no seu avanço até o nosso tempo e, sobretudo, a nossa sociedade (DAMATTA, 1981, p. 9091).

Somente no início do século XX é que se rompe com essa postura no ato da produção do conhecimento antropológico. Quando o outro externo passa a ser entendido a partir de suas particularidades.

A partir de então, a antropologia passa a provocar uma "verdadeira revolução epistemológica, que começa por uma revolução do olhar" (LAPLANTINE, 2003, p. 22). E isso implica em um "descentramento radical, uma ruptura com a ideia de que existe um "centro do mundo', e, correlativamente, uma ampliação do saber e uma mutação de si mesmo" (LAPLANTINE, 2003, p. 22-23). Aparentemente simples, esse reordenamento no entendimento do sujeito do conhecimento sobre o mundo social, trouxe às ciências humanas uma indispensável contribuição.

Continuando com os argumentos introdutórios de Laplantine, observa-se:

A descoberta da alteridade é a de uma relação que nos permite deixar de identificar
nossa pequena província de humanidade com a humanidade, e correlativamente deixar
de rejeitar o presumido "selvagem" fora de nós mesmos. Confrontados à
multiplicidade, a priori enigmática, das culturas, somos aos poucos levados a romper
com a abordagem comum que opera sempre a naturalização do social (como se nossos
comportamentos estivessem inscritos em nós desde o nascimento, e não fossem
adquiridos no contato com a cultura na qual nascemos) (LAPLANTINE, 2003, p. 23).

Portanto, no início do século XX, quando esta ciência social começou a romper com sua visão etnocêntrica originária, os povos existentes fora do eixo França/Inglaterra/Estados Unidos, passaram a ser vistos em suas características específicas. Era necessário, a partir de então, analisar as formas sociais e culturais das sociedades externas ao Ocidente, sem um olhar pautado na pretensa superioridade do "civilizado". O outro deveria ser enxergado a partir de 
sua complexidade própria. Assim, o antropólogo estaria encarregado de revelar toda a riqueza cultural e também social, daqueles antes vistos como inferiores e bárbaros. A humanidade começava a se revelar em sua real concretude.

Nas palavras de Malinowski, em seu trabalho Argonautas do pacífico ocidental, publicado em 1922, encontra-se o seguinte:

Foi-se o tempo em que se aceitavam relatos nos quais o nativo aparecia como uma caricatura infantil do ser humano. Relatos desse tipo são falsos - e, como tal, a ciência os rejeita inteiramente. O etnógrafo de campo deve analisar com seriedade e moderação todos os fenômenos que caracterizam cada aspecto da cultura tribal sem privilegiar aqueles que lhe causam admiração ou estranheza em detrimento dos fatos comuns e rotineiros. Deve, ao mesmo tempo, perscrutar a cultura nativa na totalidade de seus aspectos. A lei, a ordem e a coerência que prevalecem em cada um desses aspectos são as mesmas que os unem e fazem deles um todo coerente (MALINOWSKI, 1978, p. 24).

Uma das questões centrais desta passagem é que o trabalho do antropólogo deve ser efetivado sem a presença de certos princípios de superioridades moral e cultural diante das sociedades analisadas. Em outras palavras, ausente de condutas etnocêntricas. Sobre o trabalho etnográfico, Malinowski afirma que o

autor é, ao mesmo tempo, o seu próprio cronista e historiador; suas fontes de informação são, indubitavelmente, bastante acessíveis, mas também extremamente enganosas e complexas; não estão incorporadas a documentos materiais fixos, mas sim ao comportamento e memória de seres humanos (MALINOWSKI, 1978, p.18-19).

A partir dessa argumentação, o pesquisador deve se tornar parte da organização social do outro e, ao fazê-lo, acaba se tornando também alvo de suas interrogações de pesquisa. A apreensão do real, portanto, não passa pelo corte entre sujeito/objeto.

Nos dias atuais, a antropologia também tem contribuído enormemente para a compreensão de inúmeros grupos sociais perseguidos e marginalizados cultural e socialmente no próprio centro das sociedades ocidentais. Tudo na tentativa de se criar relações sociais em que o outro seja entendido e tratado de modo digno e respeitoso. Para garantir este trabalho de conhecimento da cultura e da organização social do outro, o "antropólogo deve relativizar os seus próprios valores culturais" (THOMAZ, 1995, p. 434). O que não significa colocar em prática uma postura baseada no relativismo absoluto - afinal é justamente contra certas atitudes, racistas ou intolerantes, que a antropologia vem dedicando o seu trabalho. Portanto, nem tudo deve ser relativizado. 
O fundamental da investigação antropológica é que a discussão em torno de um outro, marcado por características históricas e culturais específicas, torna-se problema central para a ciência social moderna. E essa preocupação sem dúvida extrapola o espaço cientifico puro, lançando para o âmbito da política toda a complexidade referente ao processo de construção dos vínculos sociais necessários para qualquer movimento político-cultural.

\section{Antonio Gramsci e o outro}

Diante dessa questão, como inserir o pensamento de Antonio Gramsci? Como se sabe, este sardo/italiano, esteve completamente voltado à questão da revolução comunista na Itália, em toda a sua complexidade. Tinha-se pela frente: 1) a questão da luta pelo poder políticosocial da classe operária e dos camponeses, 2) a ruptura em relação à herança históriconacional conservadora, 3) a luta contra o regime fascista, etc., tudo na tentativa de contribuir para a libertação do trabalho humano. Como, então, relacionar o tema do respeito ao outro, a um pensamento totalmente fundamentado na luta e nos conflitos existentes na realidade social?

Como já foi dito, o autor italiano não teve a intenção de formular uma antropologia, como tal é caracterizada atualmente na academia. Entretanto, também foi argumentado que isso não descarta a existência de um princípio antropológico tanto em suas ideias quanto em suas ações como militante político.

De modo geral, pode-se afirma que Gramsci não esteve apenas preocupado com o poder da "novíssima" classe social, mas fundamentalmente em como construí-lo. O revolucionário sardo/italiano esteve claramente atento ao complicado, mas necessário, processo através do qual os trabalhadores italianos poderiam dar a sua contribuição à revolução comunista mundial. E, dentre os inúmeros aspectos presentes nessa construção histórica, sem dúvida, a questão da alteridade é um elemento central. Em primeiro lugar, Gramsci não entendia a classe operária como um dado da natureza; em segundo, na sua visão, existia, para além desta classe, um conjunto enorme de grupos populares que deveria ser profundamente compreendido pelos comunistas. Em sua leitura, nem sempre os militantes responsáveis por organizar política e culturalmente os trabalhadores estavam atentos a essa questão - o que certamente colocava em xeque o surgimento do "intelectual orgânico" desta classe.

Um fato biográfico sinaliza a sua preocupação com a alteridade, demonstrado quando jovem, no contexto da Primeira Guerra Mundial. Giuseppe Fiori recupera o acontecido da seguinte forma: 
Em confronto com Rabezzana, Barberis e Giuduce, Gramsci também inovava no modo de colocar o problema das relações com os outros partidos. Battista Santhià recorda uma visita à redação de $I l$ Grido. Quatro jovens discutiam com Gramsci em tom pacato. Tratavam-se formalmente de senhor. "No final da longa conversa, percebi com imensa surpresa que se tratava de jovens católicos e que a sua oposição à guerra se diferenciava da nossa porque era exclusivamente pacifista ('Somos contra todas as guerras', diziam) e se baseava nos ensinamentos evangélicos. Gramsci, para provocarme, propôs que eu ajudasse esses jovens. Não me dei conta imediatamente da provocação e ingenuamente perguntei se devia unir-me a eles em suas orações para obter o grande milagre da paz." A seca resposta de Gramsci é narrada da seguinte forma por Santhià: "A única coisa que ensinam a vocês é um anticlericalismo estúpido, que não educa nem intelectual, nem politicamente. Não que eu vá à igreja, porque não sou crente. Mas devemos nos dar conta do fato de que os que acreditam na religião são a maioria. Se continuarmos a manter relações só com os ateus seremos sempre uma minoria. Há burgueses anti-socialistas que são ateus, zombam dos padres e não vão à igreja, e, ao mesmo tempo, são favoráveis à participação da Itália na guerra e nos combatem asperamente. Estes jovens, ao contrário, vão à missa, não são industriais e pedem apenas para trabalhar conosco no sentido de fazer cessar a guerra o mais rápido possível” (FIORI, 1979, p.131-132).

O conjunto da obra de Gramsci demonstra que essa postura não se verifica isolada, muito ao contrário. Em certo sentido, o autor, já em sua juventude, percebia a importância do convencimento político-moral no processo de construção de relações com aquele outro potencialmente revolucionário. Dado que este sujeito não é um elemento da natureza, mas uma síntese histórica de um determinado momento, a atividade revolucionária deveria ter na alteridade comunista a situação chave de relacionamento com os subalternos, com os governados. E é nesta condição que o movimento historicamente progressista pode passar da quantidade à qualidade, de uma força político-cultural esporádica ao poder hegemônico no interior do mundo social.

Gramsci entendida que a classe operária era um sujeito da história inserido numa dinâmica ininterrupta. A todo o momento, novas complexidades surgiam tanto para ela quanto para quem buscasse compreende-la. Era preciso, antes de qualquer coisa, desnaturaliza-la, pois somente assim seria possível entender cada detalhe específico do seu processo de autoconstituição histórica. Os comunistas, por esse motivo, deveriam rejeitar uma visão etnocêntrica - ou como o próprio dizia: "pedante" - perante os trabalhadores. Era necessário estabelecer um diálogo horizontal e um respeito profundo em relação a este outro. A cultura operária, seus valores, seus preconceitos, limites e potenciais, deveriam ser minuciosamente analisados.

Em relação aos órgãos de representação da classe operária, o entendimento de suas características também deveria ser obtido historicamente. Gramsci buscou não naturalizar suas funções, fixando previamente aquilo que deveria ser. Se os operários eram constituídos a partir de sínteses historicamente definidas, suas representações também o eram. Em seu artigo 
Sindicatos e conselhos, publicado em 1920, no L'Ordine Nuovo, a argumentação vai na seguinte direção:

O sindicato não é esta ou aquela definição do sindicato: o sindicato se torna uma determinada definição, ou seja, assume uma determinada figura histórica na medida em que as forças e as vontades operárias que o constituem lhe imprimem uma específica orientação e põem como meta da sua ação o objetivo que foi afirmado na definição. (GRAMSCI, 2004, V1, p. 367).

Sem um conhecimento sério, portanto, sobre quem são de fato os operários, ter-se-ia também pouca compreensão de suas potenciais organizações de representação. A relação entre um e outro é orgânica e dialética. O poder dos organismos revolucionários somente se concretiza quando a classe trabalhadora é historicizada. Tendo em vista um tal objetivo é que afirma - em seu texto pré-carcerário Por uma renovação do partido socialista, publicado também no L'Ordine Nuovo, em 1920 - o seguinte:

[...] é necessário que o Partido viva sempre imerso na realidade efetiva da luta de classe travada pelo proletariado industrial e agrícola; que saiba compreender as diversas fases e os diversos episódios desta luta, suas múltiplas manifestações, a fim de extrair a unidade da multiplicidade, de ser capaz de dar uma direção real ao conjunto dos movimentos e de infundir a convicção nas massas de que há uma ordem imanente na atual espantosa desordem (GRAMSCI, 2004, V1, p. 355).

O trabalho do militante comunista somente se torna força efetiva de transformação social quando se insere na vida da classe representada. A profunda compreensão sobre a vida dos trabalhadores, de suas lutas, suas incoerências, etc., era uma condição fundamental para a existência do próprio Partido. Até mesmo pelo fato deste ser um desdobramento da organização consciente daqueles. Para tanto, não poderia haver tratamento vertical em termos morais, no âmbito da relação dirigente/dirigido. Seguindo este seu raciocínio, Gramsci crítica a extrema esquerda comunista:

[...] a extrema esquerda define o Partido (deixando de lado, ou subestimando, seu conteúdo social) como um "órgão" da classe operária, que se constitui pela síntese de elementos heterogêneos. O Partido, ao contrário, deve ser definido pondo-se em destaque, antes de mais nada, o fato de que ele é uma "parte" da classe operária. O erro na definição do Partido leva a uma errada formulação dos problemas da organização e da tática (GRAMSCI, 2004, V2, p. 345).

Por fim, e ainda sobre o Partido, o autor diz que uma das atividades a ser desenvolvida pelos militantes era justamente a capacidade de trabalhar entre as massas,

de marcar uma contínua presença em seu seio, de estar na primeira fila de todas as lutas, de saber em todas as ocasiões assumir e manter a posição que é própria da vanguarda do proletariado. Enfatiza-se este ponto porque a necessidade do trabalho subterrâneo e a errada ideologia da "extrema esquerda" produziram uma limitação da 
capacidade de trabalho entre as massas e com as massas (GRAMSCI, 2004, V2, p. 354-55).

Como é possível perceber, "vanguarda" para Gramsci não se coloca em termos de superioridade moral e intelectual dos dirigentes sobre os dirigidos. Vanguarda aqui é em termos políticos, isto é, sobre o grau de organização política conquistado por uma parte da própria classe operária. Outro aspecto interessante de se notar, nesta reflexão gramsciana, corresponde ao que ele chama de "trabalho subterrâneo". Será esta uma atividade semelhante àquela que em antropologia assume a definição de "etnografia"?

Assim como o trabalho do antropólogo é compreender e revelar a riqueza e a complexidade do outro, que pode ser um grupo ou uma sociedade, o comunista deveria ter a mesma postura sobre o seu outro específico: a classe trabalhadora. Gramsci percebia que muitas vezes os trabalhadores eram totalmente desconhecidos pelos seus "representantes". Aqui, está condensada toda a tarefa não apenas do "intelectual orgânico", mas também do "intelectual nacional-popular”. O partido comunista não deveria ser entendido como para a classe, mas sim da classe. As instituições revolucionárias deveriam ser a clara expressão do movimento dos trabalhadores. O intelectual nacional-popular estava encarregado de entender profundamente a sua subjetividade, os seus valores, a sua cultura, os seus anseios, entre outros elementos. (Reis, 2009) Como nenhuma classe explorada pode ser entendida a partir de abstrações, o comunista deveria efetivar, ao que parece, um trabalho etnográfico específico.

Entretanto, é importante ressaltar que essa "tradução", feita pelo autor, partindo de certos princípios antropológicos, em direção de uma específica antropologia comunista, não objetiva se desenvolver a partir das técnicas e da rigidez, muitas vezes exigidas pela ciência. Afinal, o conhecimento que surge desse trabalho etnográfico dos comunistas deve tender ao enfraquecimento da dimensão do outro e ao fortalecimento da dimensão do nós. Quando quem analisa tende a se transformar, na sua relação com o analisado, em uma síntese, em algo novo. Nos Quaderni, o autor alerta para o fato de que: “o elemento popular 'sente', mas nem sempre compreende ou sabe; o elemento intelectual 'sabe', mas nem sempre compreende e, menos ainda, "sente"” (GRAMSCI, 2001, V2, p. 1505). Portanto, não deve haver sobreposição hierarquizada de um "ente" sobre outro, mas uma unidade dialética e histórica.

Sobre o caso dos inúmeros grupos populares que existiam na Itália, o autor também demonstrou a mesma preocupação. Tanto quanto a classe operária que se apresentava com um certo grau de delineamento político, social e cultural - e que era preciso conhecê-la e desnaturaliza-la permanentemente - Gramsci percebe a necessidade de entender profundamente um outro universo popular bastante complexo, definido genericamente como o "camponês". 
Aqui as tarefas eram muito mais desafiadoras, afinal o nível de complexidade que envolvia esse enorme grupo popular era bastante alto. Os camponeses também não podiam ser entendidos em bloco, não eram homogêneos. Existia uma diversidade cultural/linguística/política que necessitava de uma compreensão séria por parte dos comunistas. $\mathrm{O}$ aspecto subjetivo do camponês tinha que ser apreendido para se projetar específicas formulações e práticas políticas.

Em contextos de pouca ruptura em relação ao mundo feudal, os camponeses de certos países europeus, não tinham absorvido determinadas leituras que os situassem no interior dos conflitos de classe, inaugurados com a confirmação histórica do capitalismo. Diz o autor, em Operários e camponeses de 1919:

\begin{abstract}
A psicologia dos camponeses era, em tais condições, algo que escapava de qualquer controle; os sentimentos reais permaneciam ocultos, envolvidos e confundidos num sistema de defesa contra as explorações, meramente egoísta, sem continuidade lógica, que se materializava em muita dissimulação e servilismo fingido. A luta de classes se confundia com o banditismo, com a vingança, com o incêndio dos bosques, com o morticínio do gado, com o rapto das mulheres e das crianças, com o assalto à prefeitura: era uma forma de terrorismo elementar, sem consequências estáveis e eficazes. Objetivamente, portanto, a psicologia do camponês se reduzia a uma pequeníssima soma de sentimentos primitivos dependentes das condições sociais criadas pelo Estado democrático-parlamentar: o camponês era deixado completamente à mercê dos proprietários e de seus sicofantas e dos funcionários públicos corruptos; e a sua maior preocupação vital era a de defender-se corporalmente dos perigos da natureza elementar, dos abusos e da barbárie cruel dos proprietários e dos funcionários públicos. O camponês sempre viveu fora do domínio da lei, sem personalidade jurídica, sem individualidade moral: conservou-se como um elemento anárquico, o átomo independente de um tumulto caótico, refreado somente pelo medo da polícia e do diabo. Não compreendia a organização, não compreendia o Estado, não compreendia a disciplina; paciente e tenaz no esforço individual de extrair da natureza escassos e magros frutos, capaz de enormes sacrifícios na vida familiar, era selvagemente impaciente e violento na luta de classes, incapaz de propor-se um objetivo geral de ação e de persegui-lo com perseverança e luta sistemática (GRAMSCI, 2004, V1, p. 265-66).
\end{abstract}

Como é possível perceber, existe, nessa passagem, um grande esforço em tentar compreender o universo político-cultural dos camponeses. Inúmeros equívocos poderiam ser evitados, a partir de tal conhecimento. A preocupação pode ser justificada historicamente com o exemplo concreto dos revolucionários russos do século XIX que lançaram a conhecida e fracassada palavra de ordem "ir ao povo", com evidente referência aos camponeses. Como se sabe, a política de aproximação dos "amigos do povo" aos oprimidos da Rússia, não ocorreu como tinham planejado, pois, na maioria das vezes, acabaram sendo denunciados às autoridades pelos próprios camponeses. Entre

1873 e 1877, nada menos que 1.611 narodniks foram presos, 844, condenados. Menos de $10 \%$ tinham origem camponesa. A grande maioria provinha de famílias de nobres, de sacerdotes - popes -, de funcionários ou de comerciantes. Em nome do povo, e de 
seus interesses, os filhos ricos da cidade queriam levantar os miseráveis do campo. (REIS, 1997, p. 31).

Ainda antes de ser preso pelo regime fascista, Gramsci escreveu em A questão meridional, em 1926, que tanto os comunistas quanto a classe operária do Norte, deveriam compreender seriamente os camponeses do Sul. Para ele, de modo central:

a questão camponesa na Itália é historicamente determinada, não é a "questão
camponesa e agrária em geral"; na Itália, a questão camponesa, como consequência
da específica tradição italiana, do específico desenvolvimento da história italiana,
assumiu duas formas típicas e peculiares, ou seja, a questão meridional e a questão
vaticana. Portanto, conquistar a maioria das massas camponesas significa, para o
proletariado italiano, assumir como próprias estas duas questões do ponto de vista
social, compreender as exigências de classe que elas representam, incorporar tais
exigências entre suas próprias reivindicações de luta (GRAMSCI, 2004, V2, p. 408-
09).

A questão do entendimento do outro, era aqui indiscutível. Como já salientado, eram muito presentes na Itália do início do século XX, ideologias de cunho racistas lançadas para explicar o "sulista", em especial o "camponês". Diziam que os motivos da miséria dessa população estavam em sua inferioridade biológica, em sua preguiça natural. Essa visão, não raramente, podia ser percebida entre os operários do Norte. E isso foi identificado por Gramsci. Assim, o trabalho etnográfico dos militantes era não apenas para inserir os camponeses no movimento comunista, mas também para viabilizar a união destes com os trabalhadores urbanos do Norte. Somente com a produção de um conhecimento revolucionário sobre este universo popular é que o racismo poderia desaparecer entre os operários.

No âmbito do Partido, seus membros tinham a responsabilidade de estabelecer um contato com esse outro, potencialmente revolucionário, partindo do respeito ao seu folclore, aos seus costumes particulares, ao seu dialeto, etc. Somente desprovidos de posturas hierarquizadoras ou pedantes (etnocêntricas), os militantes poderiam desmontar certar crenças e seriam capazes de ampliar uma visão de mundo até então provinciana, em direção do universal (hegemonia). E aqui, o processo é visualizado pela dialética entre o particular e o geral que visa o surgimento de algo novo, de uma síntese. Gramsci não vê a cultura das províncias de um ponto de vista iluminista, em que o progresso se coloca como inexorável. Para ele, a imposição de valores "universais" e a tentativa de destruição, sem as devidas mediações, deste mundo pequeno e terrível é tão ineficaz quanto a pretensão de destruir o "mundo grande" e desumanizador, sem as corretas relações com o particular. Portanto, existe uma dialética entre província e mundo que deve ser percebida como condição sine qua non para a criação de um movimento comunista de fato popular. Mesmo quando o autor afirma que os operários devem 
“dirigir” os camponeses, a sua concepção é puramente política. Não existe qualquer influência da ciência positivista defensora de uma superioridade racial do Norte sobre o Sul (camponeses).

Um dos problemas centrais colocados para os subalternos, diz respeito justamente ao modo como pensam a realidade social e a sua cultura. Para Gramsci, as classes e os grupos subalternos se caracterizam pela subordinação político-cultural à hegemonia das forças dominantes. Segundo Kate Crehan, a leitura de Gramsci define que

o caráter básico da cultura subalterna deriva do fato de estar 'historicamente na defensiva'; a questão do poder está no centro de sua teoria da cultura. Isso explica sua frequente utilização do termo 'subalterno' em suas análises da mentalidade dos subordinados. É sua subordinação, seu caráter subalterno, o que determina sua forma de ver o mundo (CREHAN, 2004, pp.121-22).

Dito ainda de outro modo, a forma como entendem o mundo é

em parte um produto de sua posição subordinada e dominada. Sua visão do mundo se forma necessariamente no contexto de vidas vividas em condições de subordinação e de concepções hegemônicas que refletem a visão do mundo nascida da perspectiva dos grupos dominantes da sociedade. Porém é a partir da experiência vivida da subordinação que com o tempo podem emergir as concepções contra-hegemônicas da realidade ainda que no princípio somente de forma embrionária (CREHAN, 2004, p. 137-38).

Entender o subalterno, como é possível perceber, está intimamente ligado à questão da construção de uma hegemonia antagônica ao capital. Se por um lado, a subordinação de classes e grupos à hegemonia dos dominantes dificulta o autoconhecimento daqueles, por outro, as suas vidas marcadas pela exploração e pela miséria podem fomentar o surgimento de novas visões sobre a realidade, promotoras de saídas revolucionárias para tal situação.

Numa perspectiva universal e historicista, o subalterno inventado pela civilização ocidental não se restringe ao mundo oriental, afinal caracterizações semelhantes foram lançadas a certos grupos e classes internos ao próprio Ocidente. Controlar os desejos desse outro inferior também deveria ser uma prioridade. Em outras palavras:

A irrupção do outro interno sempre foi vista pelo Ocidente como uma ameaça à sua estabilidade e identidade; e assim foram encaradas as tantas insurreições camponesas, que eram associadas a heresias. $\mathrm{Na}$ época da modernidade, que começa a encontrar passagem desde a revolução burguesa na Inglaterra, esse outro interno negativo, ameaçador da ordem do Ocidente, que na concepção liberal viria a se chamar despotismo, toma a forma da democracia, que poderia projetar os produtores diretos para a ação política (DEL ROIO, 1998, p.101).

Em tal perspectiva, o "subalterno" não é construído apenas a partir do mundo econômico, já que é forjado também nas formulações políticas e culturais das classes dominantes ocidentais. 
Com isso, era indispensável o combate a todo um universo cultural baseado na mistificação de realidades historicamente determinadas. As classes dominantes para se manterem no controle social, naturalizaram inúmeras situações históricas, retirando de cena as contradições do capitalismo. Assim, todo um conjunto de pensamentos elaborados para transformar a realidade em algo desprovido de antagonismos, deveria ser combatido pelos comunistas.

No campo das chamadas superestruturas, Gramsci identifica uma série de elementos mistificadores e prejudiciais ao desenvolvimento do conhecimento crítico e sistematizado das classes e dos grupos subalternos. Um caso exemplar, dava-se sobre a filosofia. Diz o autor, em seus Quaderni:

É preciso destruir o preconceito, muito difundido, de que a filosofia é algo muito difícil pelo fato de ser a atividade intelectual própria de uma determinada categoria de cientistas especializados ou de filósofos profissionais e sistemáticos. É preciso, portanto, demonstrar preliminarmente que todos os homens são "filósofos", definindo os limites e as características desta "filosofia espontânea", peculiar a "todo o mundo", isto é, da filosofia que está contida: 1) na própria linguagem, que é um conjunto de noções e de conceitos determinados e não, simplesmente, de palavras gramaticalmente vazias de conteúdo; 2) no senso comum e no bom senso; 3) na religião popular e, consequentemente, em todo o sistema de crença, superstições, opiniões, modos de ver e de agir que se manifestam naquilo que geralmente se conhece por "folclore" (GRAMSCI, 2001, V2, p. 1375).

Essa sua tentativa de desmistificar determinadas concepções do mundo, criadas pela burguesia, objetiva também desmontar suas consequências para o âmbito das relações sociais construídas historicamente. Para o dirigente comunista, por exemplo, a relação filosofia/senso comum não deve assumir aspectos a-históricos, isto é, fruto de pretensas correlações sóciopolíticas fixas e naturalizadas. Suas diferenças devem ser apreendidas a partir de específicas construções arbitrárias que variam de acordo com as correlações de forças sociais. A problematização do autor, sobre o tema, desenvolve-se do seguinte modo:

$\mathrm{Na}$ filosofia, destacam-se notadamente as características de elaboração individual do pensamento; no senso comum, ao contrário, destacam-se as características difusas e dispersas de um pensamento genérico de uma certa época em um certo ambiente popular. Mas toda a filosofia tende a se tornar senso comum de um ambiente, ainda que restrito (de todos os intelectuais). Trata-se, portanto, de elaborar uma filosofia que - tendo já uma difusão ou possibilidade de difusão, pois ligada à vida prática e implícita nela - se torne um senso comum renovado com a coerência e o vigor das filosofias individuais. E isto não pode ocorrer se não se sente, permanentemente, a exigência do contato cultural com os "simples" (GRAMSCI, 2001, V2, p. 1382-83).

Gramsci visa a todo momento desnaturalizar certas concepções criadas pelas classes dominantes, fundamentalmente sobre aquelas baseadas no pressuposto de que algumas 
dimensões do pensamento seriam privilégios de poucos, dotados de poderes quase sobrenaturais.

Essa maneira de entender certas expressões da cultura geral do ser humano, está intimamente ligada à sua concepção de alteridade na relação entre dirigente/dirigido. Afinal, para se chegar a uma postura radicalmente democrática entre um e outro, era preciso criar uma concepção ampla do próprio ser humano.

O cuidado em conhecer, sempre em detalhes, o mundo do trabalho é condição indispensável para qualquer atividade que tivesse como o horizonte a construção de um projeto social hegemônico. Para tanto, Gramsci busca desnaturalizar as inúmeras dicotomias criadas socialmente para atender aos interesses das classes e dos grupos dominantes. A diferenciação entre cultura erudita versus cultura popular é um exemplo da arbitrariedade criada.

$\mathrm{Na}$ passagem acima, o autor visa desmontar a ideologia burguesa que, forçosamente, busca submeter as manifestações subjetivas das classes populares a certos padrões criados artificialmente - neste caso, quando se defende que o "senso comum" (classes populares) é um universo absolutamente separado da "filosofia" (classes dominantes). Enquanto as primeiras são inseridas ao princípio da incapacidade intelectual, as segundas, realizam-se como únicas agentes pensantes da sociedade.

Esse enunciado, importante notar, aproxima-se à afirmação antropológica acerca da impossibilidade da existência de um indivíduo/grupo/classe "sem cultura". Como argumenta Roberto DaMatta, é bastante comum no cotidiano os indivíduos associarem a palavra "cultura" ao "ser culto" e "erudito". Como o próprio autor afirma:

Cultura aqui é equivalente a volume de leituras, a controle de informações, a títulos universitários e chega até mesmo a ser confundido com inteligência, como se a habilidade para realizar certas operações mentais e lógicas (que definem de fato a inteligência) fosse algo a ser medido ou arbitrado pelo número de livros que uma pessoa leu, às línguas que pode falar, ou os quadros e pintores que pode, de memória, enumerar. Nesse sentido, cultura é uma palavra usada para classificar as pessoas e, às vezes, grupos sociais, servindo como arma discriminatória contra algum sexo, idade, etnia, ou mesmo sociedades inteiras (DaMATTA, 1986, p. 122).

Ao afirmar que "todos são filósofos", Gramsci está bastante próximo desse olhar antropológico. Laraia explicita a importância da cultura para o ser humano, da seguinte forma: "o modo de ver o mundo, as apreciações de ordem moral e valorativa, os diferentes comportamentos sociais e mesmo as posturas corporais são assim produtos de uma herança cultural, ou seja, o resultado da operação de uma determinada cultura." (Laraia, 2006, p.68) Em outras palavras, não existe, novamente recuperando DaMatta: "coletividade humana que não se 
utilize substancialmente de uma noção de sociedade ou de cultura para exprimir partes de sua realidade social." (Damatta, 1981, p. 57)

Mesmo quando o autor dos Quaderni analisa o "folclore", dimensão frequentemente considerada inferior à ciência e ao conhecimento "erudito", afirma que este tema deveria ser estudado não de modo "pitoresco". Em sua opinião,

seria preciso estudar o folclore, (...) como "concepção do mundo e da vida", em grande medida implícita, de determinados estratos (determinados no tempo e no espaço) da sociedade, em contraposição (...) às concepções do mundo "oficiais" (ou, em sentido mais amplo, das partes cultas das sociedades historicamente determinadas) que se sucederam no desenvolvimento histórico. (Daí a estreita relação entre folclore e “senso comum”, que é folclore filosófico) (GRAMSCI, 2001, V3, p. 2311).

Um elemento interessante aqui é como o autor concebe o estudo sobre o folclore, isto é, tendo em vista a possibilidade de inseri-lo às "concepções do mundo e da vida potencialmente alternativas, de oposição, que mantém a gente subalterna", mas que escapavam dos registros históricos (oficiais). (Crehan, 2004, p. 129) Restava, então, resgatar criticamente tais elementos. Segundo dizia, este elemento cultural das camadas populares não era analisado na Itália de uma maneira historicista, isto é, de um modo vivo e atuante entre as classes populares. Por isso, em muitos casos, o exótico e o caricatural acabavam sendo a forma predominante de entendê-lo.

Em termos metodológicos, Gramsci defende um instrumento específico de análise, isto é a "filologia viva", através do qual os dirigentes do Partido poderiam estabelecer uma específica relação junto às classes subalternas. Este recurso foi definido da seguinte maneira:

Com o crescimento dos partidos de massa e com a sua adesão orgânica à vida mais íntima (econômico-produtiva) da própria massa, o processo de estandardização dos sentimentos populares, que era mecânico e casual (isto é, produzido pela existência ambiente de condições e pressões similares), torna-se consciente e crítico. $\mathrm{O}$ conhecimento e o julgamento da importância de tais sentimentos jamais ocorrem, por parte dos chefes, através de intuições baseadas na identificação de leis estatísticas, isto é, por via racional e intelectual, frequentemente ilusória - que o chefe traduz em ideias-forças, em palavras-forças - mas ocorre, por parte do organismo coletivo, através da "co-participação ativa e consciente", da "co-passionalidade", da experiência dos detalhes imediatos, de um sistema que se poderia chamar de "filologia viva". Assim, forma-se uma estreita ligação entre grande massa, partido e grupo dirigente; e todo o conjunto, bem articulado, pode se movimentar como um "homemcoletivo" (GRAMSCI, 2001, V2, p. 1430).

Nota-se, portanto, o quanto o autor esteve preocupado com o processo de construção de um movimento comunista fundado na união orgânica entre dirigentes e dirigidos, partido e massa. A "filologia viva", ao que parece, não é um método formal-burocrático de análise, mas um modo de compreender e de se posicionar na vida social, interligando e dando sentido para 
os inúmeros detalhes e acontecimentos do cotidiano dos subalternos. Seria ele uma concepção etnográfica?

Enquanto recurso metodológico da "filosofia da práxis", a "filologia viva" não pode deixar de ser vista como uma maneira eficaz de compreender o real. Gramsci dava muita

\begin{abstract}
importância à filologia, entendida no sentido muito geral de expressão metodológica da importância dos fatos particulares. Ele formulou o conceito de 'filologia vivente' para destacar o valor não apenas em relação ao estudo dos textos, mas da vida social e política e da própria concepção de partido. O método da 'filologia vivente' comporta o movimento de circulação do empírico e do individual ao universal e total e viceversa, sem nunca fechar o círculo ou chegar a uma conclusão definitiva e peremptória. Trata-se de uma ideia-chave tanto na ciência como na política, no âmbito teórico e prático, seja nas dimensões da pesquisa abstrata como na análise concreta (BARATTA, 2004, p. 18-19).
\end{abstract}

Em tal método, portanto, é possível identificar aquilo que se pode chamar de princípio antropológico. Então, por mais que não tenha se voltado para o desenvolvimento da antropologia, como ramo específico das ciências humanas, Gramsci produziu um conjunto de reflexões muito próximo a ela. A sua concepção de cultura e a sua busca por um entendimento sobre a realidade baseado numa etnografia política, configuram-no como um singular antropólogo comunista.

\title{
4 Considerações Finais
}

Em linhas gerais, essas são algumas questões que colocam Gramsci próximo de um tema central da antropologia que é aquele referente à alteridade. Mesmo não citando antropólogos da época, o sardo/italiano produziu um pensamento muito próximo e semelhante a alguns deles. Num certo sentido, ele também estava fazendo antropologia.

Entretanto, Gramsci ainda não foi devidamente relacionado à antropologia, assim como o foi em outras áreas das ciências humanas. Aliás, de maneira geral, a própria relação entre antropologia e marxismo tem gerado debates bastante tensos. Infelizmente, para muitos antropólogos contemporâneos, essa corrente de pensamento não apresenta elementos que possam contribuir para o entendimento seja da cultura, seja da alteridade. Para muitos, o marxismo ainda está preso ao reducionismo, ao determinismo econômico ou mesmo ao evolucionismo positivista (TURATTI, 2011). Assim, mesmo presente no pensamento político do autor italiano um certo princípio antropológico, seus significados nem sempre são compreendidos seja pelos próprios antropólogos, seja por pesquisadores de outras áreas (CREHAN, 2004). E mesmo quando aparecem nos trabalhos de antropologia, as ideias de Gramsci, quase sempre, carecem de aprofundamento. Este autor é mais 
citado que realmente conhecido, como disse Foucault. Até agora, Gramsci tem sido na antropologia pouco mais que um nome associado ao conceito de hegemonia e, de uma maneira mais geral, a um marxismo aberto e não dogmático. (...) Em geral, os antropólogos somente entendem a hegemonia como um conceito que descreve uma forma particular de poder e não, como é o caso de Gramsci, uma forma de enfocar o problema da produção e reprodução do poder, um enfoque que obriga a apontarmos determinadas perguntas sobre as realidades empíricas do poder (CREHAN, 2004, p. 186).

Portanto, é preciso notar no pensamento do autor dos Quaderni, a sua devida importância para essa área do conhecimento. Ao mesmo tempo, no interior da produção dos estudiosos gramscianos, essa dimensão antropológica no pensamento do autor, deve ter maior presença e visibilidade. Afinal, toda a discussão acerca do consenso e da hegemonia pode também passar por uma abordagem da alteridade. A dialética que marca a relação consenso/coerção é a mesma que pode ser estabelecida entre alteridade e antagonismo.

Os estranhamentos existentes entre um indivíduo ou grupo social em relação a um outro, devem ser percebidos a partir de determinadas construções ideológicas que asseguram tal situação. As diferenças criadas a partir daí, nada têm de natural, pois a não compreensão (ou mesmo a não aceitação) histórica do desconhecido, na verdade, tem por base específicas relações de poder. Em outras palavras, determinadas formulações político-culturais.

Gramsci é um dos autores que, no interior do marxismo, mais tornou explícita a importância das organizações comunistas compreenderem, em seus mínimos detalhes, a vida concreta do proletariado seja da cidade ou do campo. Essa tarefa se torna decisiva para qualquer projeto social que tem por objetivo a transformação radical da própria sociedade. A hegemonia do mundo do trabalho sobre a vida social depende de um vínculo moral e ético entre dirigente comunista e massas operárias e trabalhadoras em geral. Para tal, o Partido e demais instituições devem compreender seriamente toda a complexidade da classe social que visa representar. Trabalho que se aproxima em muito daquele desempenhado pelo antropólogo, em sua etnografia. E assim como disse Malinowski que o "autor é, ao mesmo tempo, o seu próprio cronista e historiador", o dirigente comunista, ao se lançar à compreensão das classes subalternas, deve também estar preparado moral e eticamente para se compreender.

Gramsci visa, a todo o momento, relativizar, ou mesmo destruir, certas distinções criadas pelas classes dominantes: erudito/popular, filosofia/senso-comum, intelectual/massa, partido/classe, etc. Todas essas contraposições que são construções históricas e culturais, passaram a ser diferenças a-históricas, fixas e naturais. No entanto, o autor sardo demonstra que é possível ver senso-comum na filosofia, assim como filosofia no senso-comum. Esses "mundos" que aparentemente são colocados como naturalmente opostos são, na verdade, 
expressões de certas concepções ideológicas. Busca-se permanentemente a manutenção da ordem, por meio de construções político-culturais arbitrárias que garantem a legitimidade do poder do dominante sobre o dominado.

Sobre esse tema da existência de "mundos" diferentes, o autor italiano responde numa carta aos argumentos da cunhada, feitos depois desta ter assistido um filme intitulado Dois mundos. O enredo do filme, visto por Tatiana, correspondia à estória de uma relação amorosa impossível entre uma mulher judia e um oficial austríaco. Relação esta condenada pelo fato dos dois pertencerem a dois mundos diferentes. As reflexões de Gramsci vão no seguinte sentido:

\footnotetext{
Num de seus cartões, naquele em que me falou de suas idas ao cinema e, especialmente, do filme Dois mundos, algumas observações me deixaram perplexo. Como pode acreditar que existam estes dois mundos? Este é um modo de pensar digno dos Cem-Negros, da Ku Klux Klan americana ou das suásticas nazistas. (...) O filme é certamente de origem austríaca, típico do antissemitismo do pós-guerra (GRAMSCI, 2005, V2, p. 89).
}

Em outra carta, o autor continua a discussão sobre o tema (GRAMSCI, 2005, V2, p. 100-01). O fundamento da argumentação é o de que as diferenças sociais, existentes numa dada sociedade, devem ser analisadas a partir de determinadas relações de forças políticas e culturais. De modo indireto, Gramsci aqui está afirmando que o mundo dos intelectuais comunistas é o mesmo vivido pelas massas trabalhadoras. Mundo este que deveria ser permanentemente interrogado e analisado por ambos envolvidos na transformação radical da sociedade capitalista.

Mundo do trabalho e mundo do capital, por exemplo, são diferenciações históricas, frutos de lutas políticas e culturais próprias. Não são separados por um abstrato corte do real, mas, ao contrário, unidos por uma dialética entre elementos antagônicos que tende, sempre, à criação de algo novo.

Identificar as classes trabalhadoras como sendo desprovidas de inteligência é contribuir para que "os mundos" sejam vistos como dotados de vidas autônomas, quase sempre a partir de hierarquias éticas. Este é um erro que os comunistas não devem cometer.

\section{Referências}

BARATTA, G. As rosas e os cadernos: o pensamento dialógico de Antonio Gramsci. Rio de Janeiro: DP\&A, 2004.

CREHAN, K. Gramsci, cultura y antropologia. Barcelona: Bellaterra, 2004.

DAMATTA, R. Relativizando: uma introdução à antropologia social. Petrópolis-RJ: Vozes, 1981. 
Você tem cultura? In: Explorações: ensaios de sociologia interpretativa. Rio de Janeiro: Rocco, 1986.

DEL ROIO, M. O império universal e seus antípodas: a ocidentalização do mundo. São Paulo: Ícone, 1998.

FIORI, G. A vida de Antonio Gramsci. Rio de Janeiro: Paz e Terra, 1979.

GRAMSCI, A. Quaderni del carcere. Edizione critica dell'Istituto Gramsci - A cura di Valentino Gerratana, Torino: Einaudi, V2, 2001.

Quaderni del carcere. Edizione critica dell'Istituto Gramsci - A cura di Valentino Gerratana, Torino: Einaudi, V3, 2001.

. Escritos políticos. Rio de Janeiro: Civilização Brasileira, V1, 2004.

Escritos políticos. Rio de Janeiro: Civilização Brasileira, V2, 2004.

Cartas do cárcere. Rio de Janeiro: Civilizações Brasileira, V.2, 2005.

LAPLANTINE, F. Aprender antropologia. São Paulo: Brasiliense, 2003.

LARAIA, R. de B. Cultura: um conceito antropológico. Rio de Janeiro: Jorge Zahar, 2006.

MALINOWSKI, B. Argonautas do Pacífico Ocidental, In: Os pensadores. São Paulo: Abril Cultural, 1978.

ORTIZ, R. Notas sobre Gramsci e as ciências sociais. Revista Brasileira de Ciências Sociais, Vol. 21, nº 62, outubro, 2006.

REIS, C. O nacional-popular em Antonio Gramsci. Tese (Doutorado), Universidade Estadual de Campinas - UNICAMP, SP, 2009.

REIS, D. A. Uma revolução perdida: a história do socialismo soviético. São Paulo: Fundação Perseu Abramo, 1997.

THOMAZ, O. R. A antropologia e o mundo contemporâneo: cultura e diversidade, In: (Orgs) Silva e Grupioni A temática indígena na escola: novos subsídios para professores de $1^{\circ}$ e $2^{\circ}$ graus. Brasília: MEC/MARI/UNESCO, 1995.

TURATTI, M. C. M. Antropologia, economia e marxismo: uma visão crítica. São Paulo: Alameda, 2011.

Recebido em fevereiro de 2018

Aprovado em junho de 2018 